\title{
Acronymophilia: an update
}

\author{
David Isaacs, Dominic Fitzgerald
}

\begin{abstract}
The history, epidemiology, clinical features, and treatment of the epidemic infection, acronymophilia, a sinister scourge of modern medicine are described. (Arch Dis Child 2000;83:517-518)
\end{abstract}

Keywords: acronym; humour

An acronym, according to the Shorter Oxford Dictionary (or SOD) is a "word formed from initial letters of other words, e.g., Nato, radar". In common parlance, the term may also be extended to using the initial letters in place of the full term, even when these initials do not spell a word, for example, BMJ for British Medical fournal.

In this article we describe the history, epidemiology, clinical features, and treatment of the epidemic infection, acronymophilia, a sinister scourge of modern medicine.

\section{History}

Acronymophilia as a disease, entered the medical lexicon in 1994. Professor Tsung O Cheng, possibly himself an acronym, wrote an article under this heading and broke at least one record by quoting 10 references, on all of which he was the sole author, thus putting up his citation index several points at a single stroke.

The authors first became aware of this condition in the 1980s when a friend, a consultant geriatrician, was asked to talk on the topic of AIDS at an old people's home, and borrowed some slides to illustrate his talk. He reported back that his lecture was met with some bewilderment, as the audience was expecting to hear about walking aids and hearing aids.

\section{Epidemiology}

Acronymophilia is essentially a bureaucratic infectious disease or buropathy. The World Health Organisation (WHO?) was an early high profile example, but the disease has spread rapidly within the medical and scientific community. It is more prevalent in the USA (urinary streptococcal antigen), ${ }^{2}$ but is expected to increase rapidly in developing countries, whose adoption of the ISAAC trials of asthma ${ }^{3}$ has tempted one of the authors of this article to drop the "s" from the end of his surname, and increase his personal references into the thousands.

\section{Clinical features}

It is well known that certain groups are at high risk of acronymophilia.

Intensivists are particularly prone to the condition, and within intensive care units (ICUs) acronymophilia clearly operates as an hospital acquired infection (HAI). Even the term ICU is thought to derive from the patient's lament, "ICU, but U can't see me, I'm covered in tubes, like a Christmas tree".

The neonatal form of intensive acronymophilia is highly virulent. The special care baby unit (or SCBU) was the forerunner of the modern neonatal intensive care unit (NICU). The neonatal ward round is justifiably fêted as one of the prime examples of acronym abuse, with medical and nursing staff indulging in a veritable orgy of acronymic terms which are unintelligible to the visiting medical or nursing student. The 26 week $600 \mathrm{~g}$, SGA born by LSCS to a P3G2 24 year old with HDP and PROM for 16 hours was given CPAP at birth, Apgars 3 and 6, put on IMV at 26 on 4, 30 bpm, $\mathrm{FiO}_{2} 0.9$, with a UAC and UVC for TPN, and $\mathrm{ABGs}$ showed a $\mathrm{PaCO}_{2}$ of $60 \mathrm{~mm} \mathrm{Hg}$. The baby has a TOF, which could be a tetralogy of Fallot or a tracheo-oesophageal fistula (unless you're American, when the baby has a TEF).

A prominent scoring system for severity of neonatal disease is known as a CRIB score. ${ }^{4}$ Babies in the NICU are fed with EBM (expressed breast milk) although this practice has rarely been subjected to randomised controlled trials, and thus cannot be said to follow EBM (evidence based medicine).

In outpatients, the use of the term DNA is fraught with problems. The outpatient's clerk intends this to mean "did not attend". Unfortunately, however, it is open to misinterpretation by the geneticist who thinks a sample has been sent for deoxyribonucleic acid analysis, while the Consultant for Learning and Other Difficulties thinks a referral has been made to the National Dyslexic Association.

The most extreme complication of acronymophilia is the malignant sexual form known as acronymphomania which predominantly infects infectious disease (ID) physicians. The promiscuity of the acronymphomaniac puts him or her at high risk of acquiring STDs (sexually transmitted diseases) such as AIDS. The only known cure is abstinence, which makes the heart grow FONDA (full of new directions and aims).

\section{Treatment}

Sufferers from acronymophilia need to be treated with sympathy and understanding, and offered tender loving care, not TLC. However, peer review may not be sufficient to expunge the acronym from consciousness. As an alternative to exorcism, acronymophiliacs should be encouraged to join AA (Acronymophiliacs Anonymous) who operate on the following 15 point plan:

- Acknowledge the gross addictive risk (AGAR)

- Confess the real problem (CRP) 
- Renounce TLAs (three letter acronyms)

- Order more pathology (OMP)

- Never shirk uncertainty (NSU)

- Yield not unto the temptation to abbreviate (Y-not?)

- Minimise initial contact (MIC)

- Offend not against the Gods of Grammar: onomatopoeia before acronymophilia

- Pray with contrition for redemption (PCR)

- Halt initial verbosity (HIV)

- Investigate new horizons (INH)

- Litigate, don't mitigate (LDM)

- Illness is only a state of mind (ISM), unless you suffer from it

- Ask not for forgiveness (ANF), only remission

- Consolidate by cancelling (CBC) your subscription to JAMA, and other acronymophilic journals.

\section{Conclusions}

There is no known cure for acronymophilia, but long walks, fresh air, cold showers, and clean living will make it feel as if you live longer. The mortality, however, remains high, eventually reaching $100 \%$ (RIP).

Disclaimer: The authors have no known acronymophiliation.

1 Cheng TO. Acronymophilia. BMF 1994;309:683-4.

2 McIntosh ED, Jeffery HE. Clinical application of urinary streptococcal antigen (USA) detection in early onset group B streptococcal disease. Arch Dis Child 1992;67:1198200.

3 Sole D, Vanna AT, Yamada E, Rizzo MC. International Study of Asthma and Allergies in Childhood (ISAAC) written questionnaire: validation of the asthma component among Brazilian children. F Investig Allergol Clin Immunol 1998;8:376-82.

4 Tarnow-Mordi W, Parry G. The CRIB score. Lancet 1993;341:174.

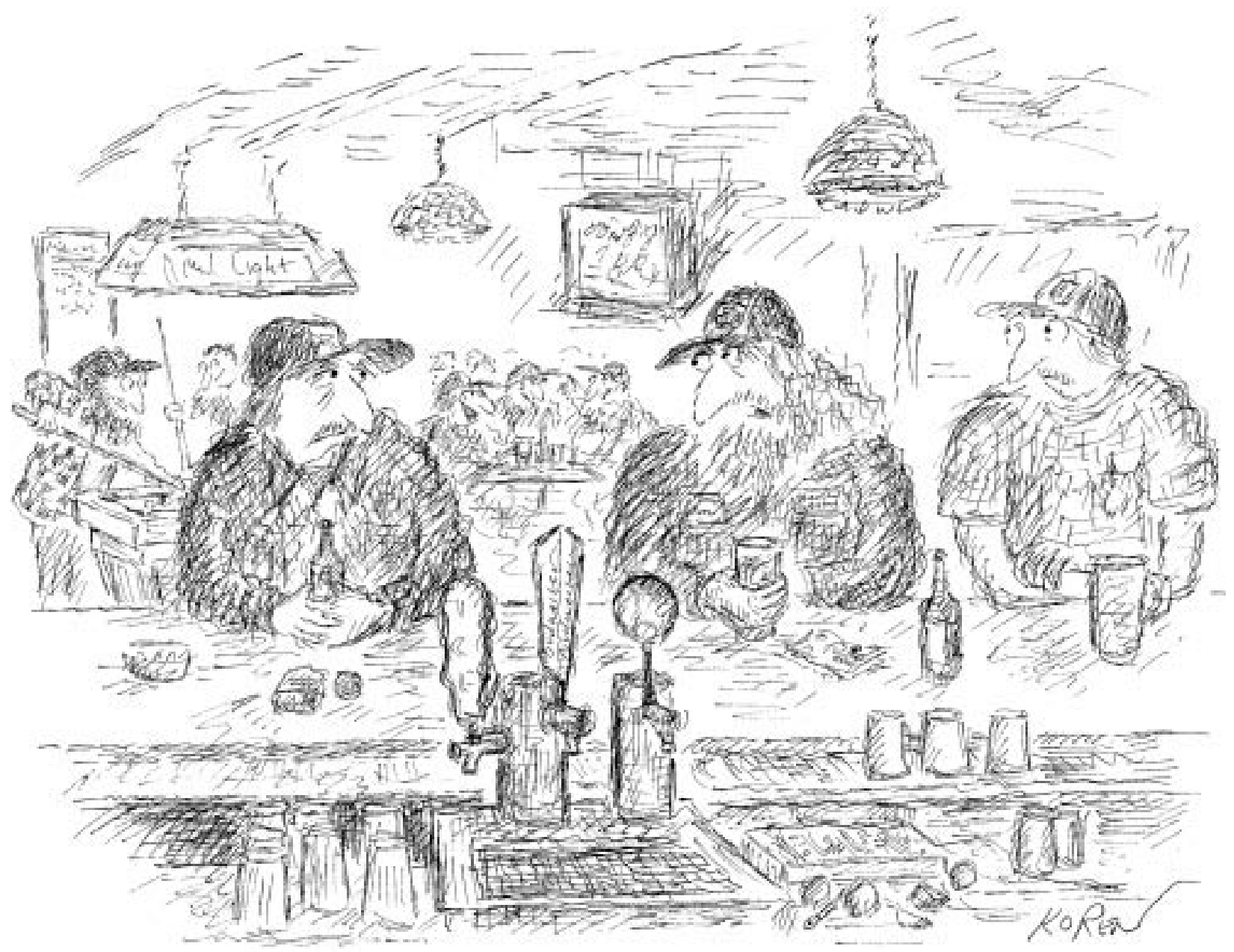

"Are you just pissing and moaning, or can you verify what you're saying with data?"

(C) The New Yorker Collection 1999 Edward Koren from cartoonbank.com. All Rights Reserved. 